\title{
Health benefits derived by reducing air pollution: An East Delhi analysis
}

\author{
Pooja Sharma ${ }^{1 *}$, Rupeesha Galhotra ${ }^{2}$, Pooja Jain ${ }^{3}$, Prarthna Aggarwal Goel ${ }^{4}$, \\ Bhoomi Aggarwal ${ }^{5}$, Drishti Narula ${ }^{6}$, Chitranshi Singh ${ }^{7}$, Juhi Dugar ${ }^{8}$, Mansi Goyal ${ }^{9}$, \\ Phalguni Sanghi ${ }^{10}$, Pragati ${ }^{11}$, Srishti Gupta 12
}

1, 2, 3, 4, 5, 6, 7, 8, 9, 10,11 Daulat Ram College, University of Delhi, New Delhi, India

\author{
Key Words \\ Air pollution \\ Health production function \\ Household surveys \\ Nutrition
}

Received: 15 January 2016

Accepted: 10 March 2017

Published: 30 June 2017

\begin{abstract}
The paper implicates the study of the health impact due to air pollution in East Delhi. Air pollution causes deterioration in the health status of people, due to which a major proportion of their income is incurred on medical expenditure. The major objective of this research is to approximately appraise the bene8it that an individual would attain in East Delhi, if there is a reduction in air pollution in this region, or similarly reiterated, an increment in the air quality of the regions located in East Delhi. The research methodology engages a household production function model which is based on a household survey of areas which are within half a kilometer distance from the main air pollution monitoring stations of the Central Pollution Control Board (CPCB) and Delhi Pollution Control Committee (DPCC) located at Anand Vihar, Nizamuddin, Shahdara and Dilshad Garden. This model is used to determine the relationships among the willingness of the people to pay for a reduction in pollution, cost of treatment, both direct and indirect costs. The method of computing the monetary benefits of reducing air pollution involves the regressing number of sick days on environment quality, mitigating activity, stock of health capital, and stock of social capital. The paper investigates that indoor pollution, ambient air pollution, and poor health stock increase the probability of falling sick. This reduced probability of falling sick implies a monetary beneBit that individuals will acquire due to a reduction in air pollution. Various factors, including nutrition, eating habits, usage of heatgenerating electronic devices, etc., are related to the number of sick days that a person has. An increase in the aforementioned independent activities decreases the dependent variable (no. of sick days). The study holds a signiBicant role in spreading awareness about air pollution among the people in Delhi and helps us to identify the reasons for high indoor pollution in various regions of Delhi. By safeguarding the health of the individuals, the society would contribute to the building up of human capital, which is more productive and efBicient, since health is a crucial constituent of human capital.
\end{abstract}

(C)2017 The Author(s). Published by TAF Publishing.

\section{INTRODUCTION}

Delhi, the national capital city of India, is one of the fastest developing cities in the world. Since it is the hub of all economic activities, it is overloaded with migrants from various areas within the country and abroad. According to 2011 census of India, population of Delhi was around 16 million (www.censusindia.gov.in , 2011). To keep up with the demands of the rapidly urbanizing territory, there has been tremendous progress in transport, education and other facilities offered by the government and other agencies in Delhi. Delhi is expected to witness a rise in population of $40 \%$ by the year 2020. An exclusive feature of

\footnotetext{
* Corresponding author: Pooja Sharma, Rupeesha Galhotra

†Email: pooja_cos@yahoo.com,rupeeshagalhotra1996@gmail.com
} 
Delhi lies in its capacity to accommodate migrated individuals who come in search for better employment and/or living conditions. Migration in Delhi accounts for more than 23\% annually of the total rise in population. Though the population seems to grow at an exponential rate in both rural and urban areas, Delhi has not been able to provide sufficient employment and jobs to its citizens. The unemployment rate in the urban area of Delhi is 40 per thousand persons in labour force in comparison to 34 per thousand in urban area at the national level.

Delhi has witnessed a redundant urbanization resulting in immense hike in indicators of pollution. Motor Vehicle emissions are considered to be a signiicant cause of the indigent air quality in Delhi. There is increased dependency of 'Ola' and 'Uber' vehicles in the city thus contributing to the rise in noxious oxidants in the air. $80 \%$ of the PM2.5 air pollution is induced by vehicular trafic and emissions released from vehicles. Other causes include exhaust from nearby industry and factory area, burning of garbage and crackers, dust from construction sites, hazardous and non-hazardous waste from industries, coal and charcoal, etc. The decreasing air quality has had an inevitable catastrophe on many residents of the city. This includes lung damage, skin damage, lowering of children's intelligence quotient and many heart related problems and diseases. An international study quotes that around 8 people die every day due to air pollution in Delhi (Source: The Hindu, February 07, 2017; Krishnadas Rajagopal). Thus, the air quality in Delhi has been the worst of any major city in the world.

As discussed, air pollution is a major element impacting the health of an individual but it is expected that the health status of an individual by increasing the nutrient intake in the form of proteins and vitamins. With air pollution being a major problem in Delhi, the present study attempted to include the nutrition factor in calculating the health benefits resulting from mitigating air pollution. The importance of nutrition for a healthy life has been deciphered into dietary recommendations indicating that one should balance calorie intake with physical activity, prefer vegetables, fruits,fibre and fish and reduce saturated fat, salt, and added sugar intake. However, behaviour change is challenging to implement, and hence it's difficult to assess its impact on health.

Westernized diets, popular in today's culture in Delhi, are portrayed by a low intake of fruits, vegetables, whole grain and ish, and a high intake of processed food items, resulting in low intake of favourable nutrients such as omega-3 PUFA and antioxidants (e.g., carotenoids and flavonoids). This lessens protection against inflammatory problems, such as air pollution. Air pollution leads to both oxidative stress and inlammation, which are pathologies underlying asthma and exacerbations of asthma. Hence, an increment in the intake of nutrients with antioxidant and/or anti-inflammatory properties has the potential to improve asthma management. Numerous studies have shown that some nutrients such as Vitamin B, C, E and D and Omega- 3 PUFA have protective effects against the damages lured by particulate matter (Péter et al., 2015). In a polluted environment a healthy diet with acceptable intake of essential micronutrients may be critical to prevent the development of chronic diseases, particularly cardiovascular and pulmonary diseases.

Epidemiological studies have centred on establishing a Household Health Production Function and Pollution Control Models through analysis of cost and damage approach, or a physical linkage approach, and other different techniques (Haque et al., 2011; Freeman et al., 1973).

An intriguing study which is analogous to this paper is done by Gupta (2008) for the Kanpur City in Uttar Pradesh, India. The study measured the monetary beneits to the people of Kanpur as a result of decrease in health damages due to reduction in air pollution. 
With a recall period of six months and maintenance of weekly health data of the people through regular entries in health diaries, the paper predicted a gain of INR 310 million per annum to the population of the Kanpur city from reduced morbidity if air quality were improved to meet the NAAEs standard. However, the study didn't include expenditures on avoiding activities and the opportunity cost of time associated with medical care.

In another study, Murty, et al. (2009) estimated a household health production function model for measuring economic beneits from reduced air pollution in the Indian cities of Delhi and Kolkata. Using six months of data relating to sick days, averting and mitigating activities, they estimated a system of simultaneous equations. The results showed a monetary beneit of INR 4897 million for Delhi and INR 3000 million for Kolkata if the level of suspended particulate matter in the air was reduced to safe limits.

Based on the Gerking and Linda (1986) model and the dose response method, Kumar and Rao (2001) also measured the monetary beneit of air quality improvement in Panipat Thermal Power Station colony in India. They estimated willingness to pay for reduced levels of pollutants (PM10) in the ambient air, which came out to be INR 21 to INR 52.5 per month for a sixty seven percent reduction in the ambient mean concentration of PM10.

Thakuri (2009) study was based on carbon stoves and pollution. The study predicted a strong correlation between $\mathrm{CO}$ and PM10 levels, and also that the indoor pollution is one of the major contributors of many health problems, resulting in high expenditure in terms of treatment and loss of productivity and efficiency.

A study on the Social Cost-Benefit Analysis of the Delhi Metro (Murty, 2009) emphasizes the saving in fuel consumption due to the use of the Delhi Metro as a mode of transport. The inter fuel substitution of petrol and CNG to electricity not only results in savings of foreign exchange but also facilitates in mitigating air pollution. The paper was based on the annual run and consumption norms of different vehicles in Delhi. The estimated fuel saved due to the diversion of traffic of cars and two-wheeler vehicles is 138.35 and 25.70 litres, with fuel savings for cars, buses and two-wheelers are INR 5260, INR 710, and INR 9770 million, respectively.

Murty and Myrick Freedman III used the hedonic property price approach while inspecting the role of climate change and thereby making climate enter utility functions. Some measures of climate as explanatory variables in the function were incorporated, thus taking advantage of the substantial variation in climate across some urban areas by pooling data from several cities. Murty 'Measuring Green GDP' (2007) computed an index of economic growth with the environmental results of that growth factored into a country's conventional GDP. It monetizes the loss of biodiversity, and accounts for the costs caused by climate change, basically subtracting resource depletion and environmental degradation from the traditional GDP figures. It approached the idea that the environmental damages are site specific and the population density and actual pollution load disclose the beneits from the reduction of a tonne of particulate matter. Adhikari (2012) on a similar path carried out a research in Kathmandu Valley, citing the 'health' beneits to a person from reducing air pollution. A related dose response function and medical expenditure function was estimated to find that a minimum of NRS 266 per year was the welfare gain to an individual in the city from reduction in air pollution.

Distinct studies have been carried out to estimate the welfare benefit to the people when they try to reduce pollution in any form. A study by Dasgupta (2004) shows identical assessment of water pollution and water borne diseases in Delhi, with a health production function approach. The purpose of utility maximizing behaviour is to estimate the probability of illness for a household, which is further analyzed to derive treatment 
costs and the wage-loss arising from illness. A related approach has been examined in the studies involving air pollution as well. All the above mentioned studies have failed to incorporate the Nutrition status of the households and its role in combating the lower air quality levels.

\section{METHODOLOGY}

The study is based on Health Production Function Model in order to assess the impact of both indoor and outdoor air pollution. Grossman (1972) developed the irst Health Production Function and used by Cropper (1981) by including pollution as one of the inputs. Gerking and Linda (1986) and Harrington and Paul (1987) have used this model to determine the relationships among the willingness of the people to pay for a reduction in pollution, cost of treatment, both direct as well as indirect costs. The only difference in all the models which use pollution as an input is whether the variable is used as a direct utility provider or as an indirect one. They also differ with respect to whether the costs of mitigation and averting are included in the pollution variable or not, or if health is taken as a capital variable.

Regression refers to measuring the relation between the mean value of one variable and corresponding value of other variables.

The method of computing the monetary benefit of reducing air pollution involves the regressing number of sick days on environment quality, mitigating activity, stock of health capital and stock of social capital.

The source of the data is common households, those which lie within half a kilometer vicinity of any of the air pollution monitoring sites taken under consideration. The health production function that was developed after careful study of external and internal factors that affect the air quality in Delhi gave us various parameters to look after when considering the causes and effects as well as a cost-benefit analysis of air pollution.

Consider a general model in which environmental quality $\mathrm{Q}$, mitigating activity MA, and aversion activity AA, stock of health capital k, and stock of social capital SK, are inputs of the health production functions.

$$
S=S(Q, M A, A A, K, S K)
$$

where $S$ represents the number of sick days.

Pollution affects individual utility indirectly through the health production function and directly by affecting outdoor recreation and many other services. The utility function of the household is defined as:

$$
U=U(X, S, Q, L, I)
$$

Where $X$ is a private good other than MA and AA consumed by the household, $L$ is the leisure, $T$ is the total time. The private good $X$ is given as a numeraire. The budget constraint of the household is:

$$
I=I^{*}+w(T-L-S)=X+P_{m} M A+P_{a} A A
$$

Given the environmental quality $Q$, and the aversion level AA, human resource capital SK, income $I$, prices, $P m$ and $P a$, the individual maximizes utility with respect to $X$, MA, AA and $L$, given the budget constraint. The solution for this equation yields the demand function for mitigating activities and averting activities of the household.

$$
M_{a x} G=U(X, S, Q, L, I)+\lambda\left(I^{*}+w(T-L-S)-X+P_{m} M A+P_{a} A A\right)
$$


The first order conditions are given as:

$$
\begin{gathered}
U_{x}=\lambda \\
U_{L}=\lambda w \\
U_{S} S \cdot M A=\lambda P_{m}+\lambda w S_{M A} \\
U_{S} S \cdot \cdot_{A A}=\lambda P_{A}+\lambda w S_{A A}
\end{gathered}
$$

From the first two conditions, we get

$$
\lambda P_{m} / S_{M A}=\lambda P_{a} / S_{A A}=U S-\lambda W
$$

The indirect utility function $V$ is given as:

$$
V=V\left(Q, P_{m}, P_{a}, S K, I, k\right)
$$

By taking the total differentiation of this function and equating it to 0 , we get,

$$
-V_{Q} / V_{I}=-V_{Q} / \lambda=d I / D_{q}
$$

Also,

$$
V_{Q}=U_{Q}+U_{S} \cdot S_{Q}-\lambda w S_{Q}=U_{Q}+\left(U_{S}-\lambda w\right) S_{Q}
$$

Substituting (11) in (10), We get,

$$
d_{I} / d_{Q}=-V_{Q} / \lambda=-\left(U_{Q} / \lambda+P_{m} . S_{Q} / S_{M A}\right)=-\left(U_{Q} / \lambda+P_{a} . S_{Q} / S_{A A}\right)
$$

By totally differentiating the household production function and equating it to 0 , Weget,

$$
S_{M A} \cdot d M A+S_{A A} \cdot d A A+S_{Q} \cdot d_{Q}=0
$$

For A Aatoptimum,

$$
-S_{Q} / S_{M A}=d M A / d Q
$$

For MA atoptimum,

$$
-S_{Q} / S_{A A}=d A A / d Q
$$

$\mathrm{dI} / \mathrm{dQ}$, the marginal willingness of an individual to pay for the reduction in environmental pollution or an increase in air quality, is the sum of direct utility gains and the indirect benefits from reduced health status through reduction in expenditure on either mitigating activities or averting activities.

Marginal Willingness to Pay MWP for gains in health beneits could be expressed in terms of Marginal rate of Technical Substitution MRTS between pollution and any other impact on health production function. Since values of marginal products of all inputs are equal at optimum. Estimating MWP requires the following:

- Estimation of health production function and evaluation of MRTS at current levels of input use and prices.

- Estimation of direct benefit requires the use of direct hypothetical observed methods of valuation, e.g. Contingent Valuation Method.

The Household Production Model underestimates the benefits from improvement in environment since it does not capture direct utility benefits to the individual. Therefore, 
it is useful to consider an alternative expression that shows the relationship between the observed $\mathrm{M}$ and $\mathrm{A}$ and the marginal willingness to pay.

Obtain the demand functions of MA and AA.

$$
\begin{gathered}
M A=M A\left(w, P_{m}, P_{a}, S, A A, Q, I, k, S K\right) \\
A A=A A\left(w, P_{m}, P_{a}, S, M A, Q, I, k, S K\right)
\end{gathered}
$$

Take the total derivative of health production function.

$$
d S / d Q=d S / d Q-\delta S / \delta M A . \delta M A / \delta Q-\delta S / \delta A A . \delta A A / \delta Q
$$

Multiplying the expression by optimal condition in (12), we get

$P_{a} .(\delta S / \delta Q) /(\delta S / \delta M A)=(U S-\lambda w) d S / d Q-(U S-\lambda w) \delta S / \delta M A . \delta M A / \delta Q-(U S-\lambda w) \delta S / \delta A A . \delta A A / \delta Q$ (20)

Rearranging,

$$
d I / d Q=w . d S / d Q+P_{m} . \delta M A / \delta Q+P_{a} . \delta A A / \delta Q+(\delta U / \delta S . d S / d Q) / \lambda
$$

The expression shows that marginal willingness to pay for health beneits from reduction in air pollution is the sum of observable reduction in cost of illness, cost of mitigating and averting activities and monetary equivalent of disutility of illness. The estimation of marginal willingness to pay (dI/dQ) using this equation requires the estimation of health production function (1) and the demand function (16) and (17). These have to be estimated as a system of simultaneous equations.

Delhi has various monitoring stations to measure ambient air pollution level, managed by institutions like CPCB and Delhi Pollution Control Committee (DPCC). The sites for household data are located close to (within half a kilometre) the monitoring station so that the household data are mapped with outdoor pollution data to estimate welfare beneits. There are about 17 sites across Delhi where the monitoring stations are located. Each site has a monitoring station, located on the roof top of a building located at the centre of the region, mostly the Electricity Board Centre. Each station has a device which provides the ambient air quality data in form of air quality indicators like $\mathrm{NO}_{2}, \mathrm{SO}_{2}, \mathrm{CO}, \mathrm{PM} 2.5$, PM10, and Ozone. These are the indicators of outdoor pollution.

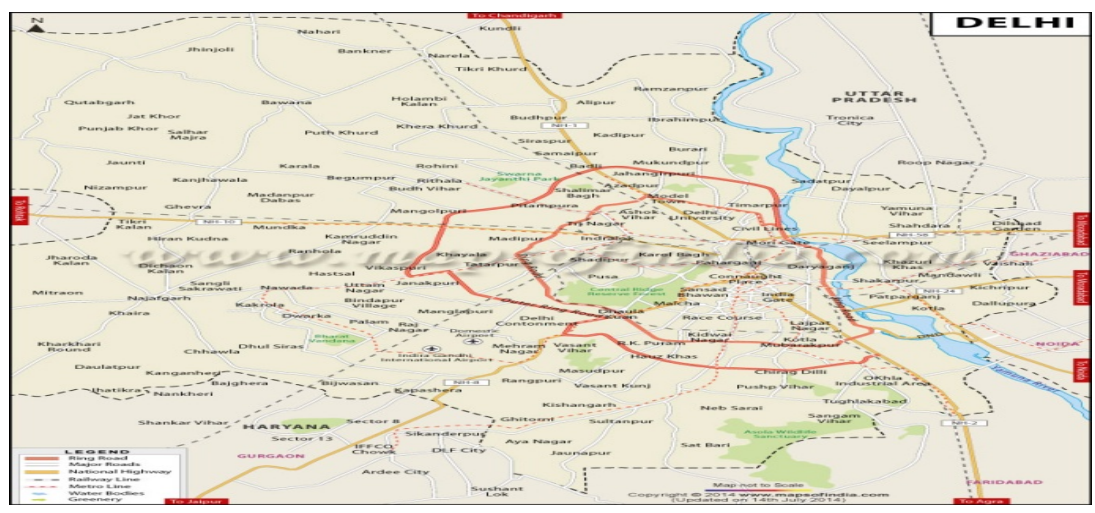

FIGURE 1. Map of New Delhi 


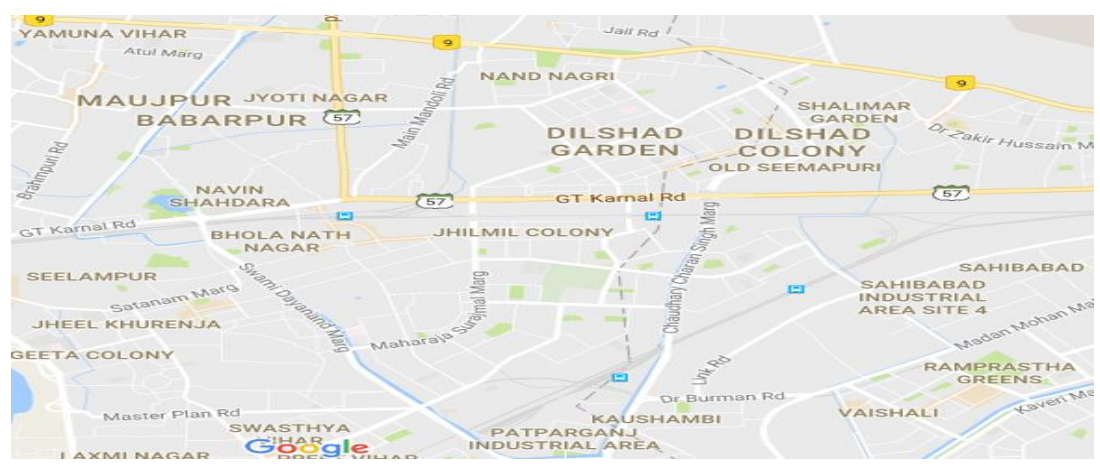

FIGURE 2 . Zoomed in Map of East Delhi showing Anand Vihar, Nizamuddin, Shahdara, Dilshad Garden

Four sites namely Anand Vihar, Nizamuddin, Shahdara and Dilshad Garden were considered for the survey. These sites have been chosen for their high pollution levels due to presence of a number of industries and ilthy conditions of the nearby located slum areas. The lower income households fail to afford pollution averting devices such as chimneys, exhaust fans, masks etc. which causes serious impact on health of people in East Delhi. Primary survey of the households was conducted by a team of student surveyors through random sampling. Face-to-face interviews were conducted by the team. The survey questionnaire had household information regarding total number of people living in that household, type of house, location, property price and economic conditions of the household. Second section included health factors like general health information, chronic diseases, and health insurance, nutrition and food habits. Section three dealt with indoor pollution measured by use of electronics, sanitation products, fuels, furniture, house fumigation, wall paints, mitigating and averting activities. The last section dealt with outdoor pollution incorporating number of vehicles, garbage disposal methods and ambient air quality.

The meter locations for the sites are:

- Nizamuddin: BSES

- Shahdara: BSES

- Dilshad Garden: IHBAS, Dayanand Hospital

The areas covered at SITE 1 Anand Vihar (AV) are:

1. Jagriti Enclave

2. Kaushambi

3. Parparganj

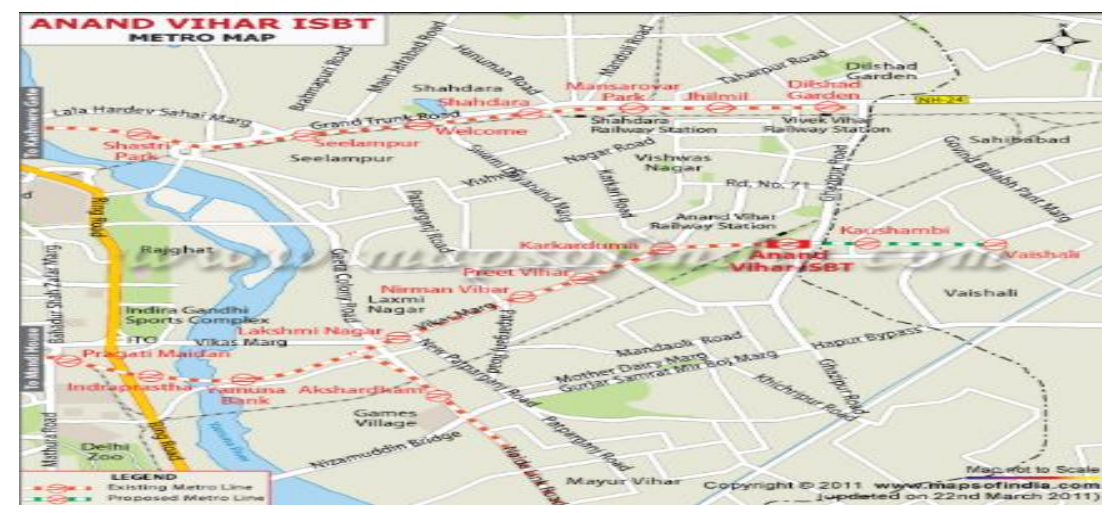

FIGURE 3 . Areas covered at site 1 Anand Vihar (AV) 
The areas covered at SITE 2 Nizamuddin (NZ) are:

1. Hazrat Nizamuddin Bridge

2. Musair Khana

3. Nizamuddin Slum Area and Police Colony

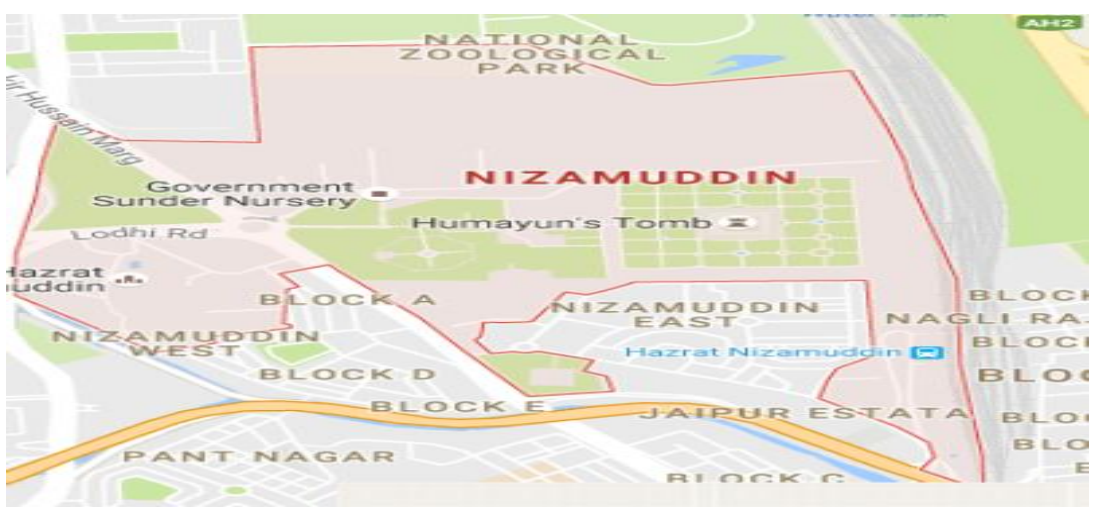

FIGURE 4. Areas covered at site 2 Nizamuddin (NZ)

The areas covered at site 3 Shahdara (SD) are: 1. BSES (Meter Location)

2. Yamuna Vihar

3. Gokul Vihar

4. Kabir Nagar

5. Gagan Vihar

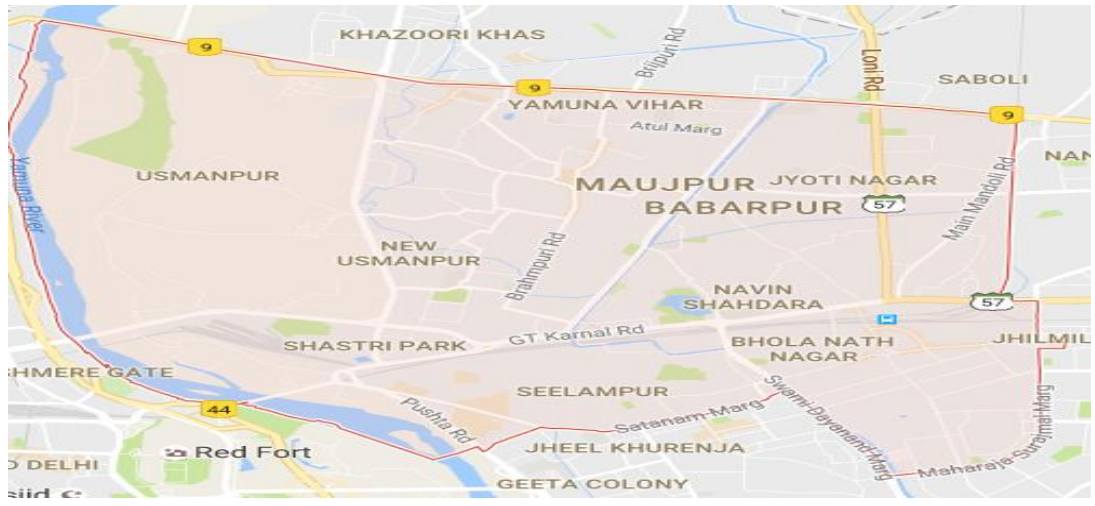

FIGURE 5. Areas covered at site 3 Shahdara (SD)

The areas covered at SITE 4 Dilshad Garden (DG) are:

1. Tahirpur

2. Jagat Puri

3. Jhilmil Colony

4. Jawala Nagar

5. Mansarovar Park

6. GTB Hospital

7. Ram Nagar 


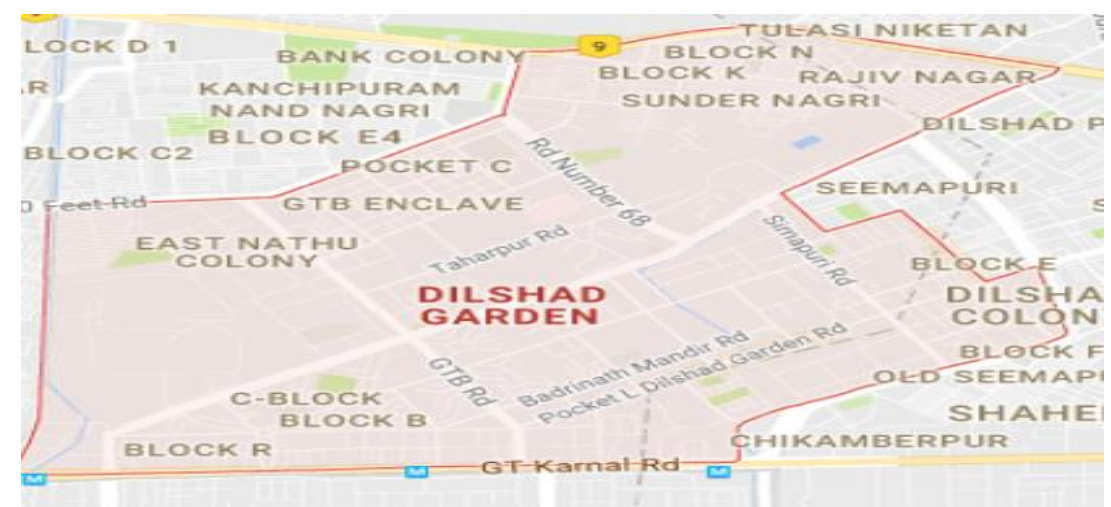

FIGURE 6. Areas covered at site 4 Dilshad Garden (DG)

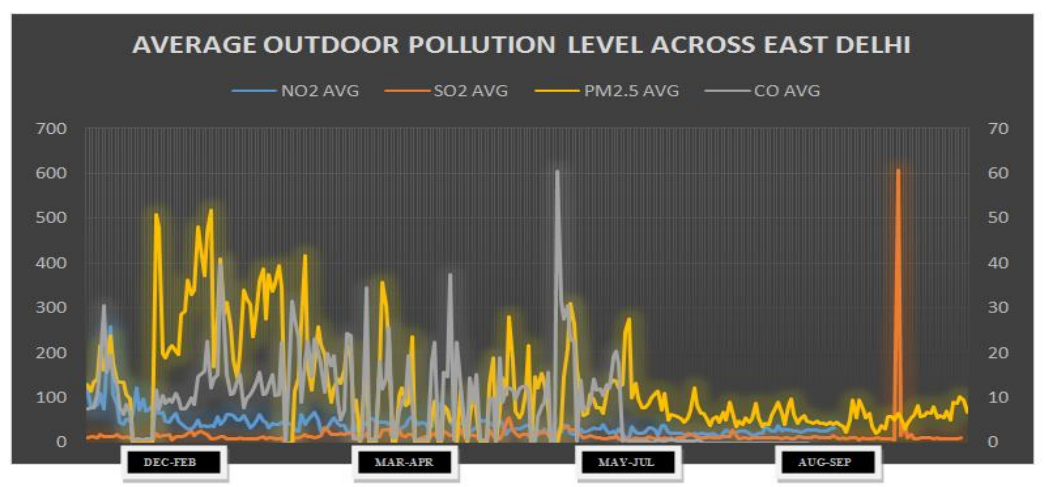

FIGURE 7. Average outdoor population level across east Delhi

In the East Delhi Region, $\mathrm{CO}$ and $\mathrm{SO}_{2}$ monthly averages have been signficantly high, $\mathrm{CO}$ exceeding the threshold level by larger gap. This sudden acute rise in $\mathrm{CO}$ is observed in summer season while acute rise in $\mathrm{SO}_{2}$ is seen in the autumn season. PM2.5 which is considered as crucial indicator of high degree of pollution reaches its higher levels in the winter season, starts reducing in summer and reaches lower levels in autumn. While $\mathrm{NO}_{2}$ maintains a medium level throughout the year and attains its peak in winter, lower than all other indicators of outdoor pollution. The observation regarding $\mathrm{SO}_{2}$ is quite unique in the sense that it remains low throughout the year but attains a peak level in autumn. A sudden acute jump can be attributed to some incident in East Delhi which involved coal burning. All the parameters have attained low values during the rainy seasons.

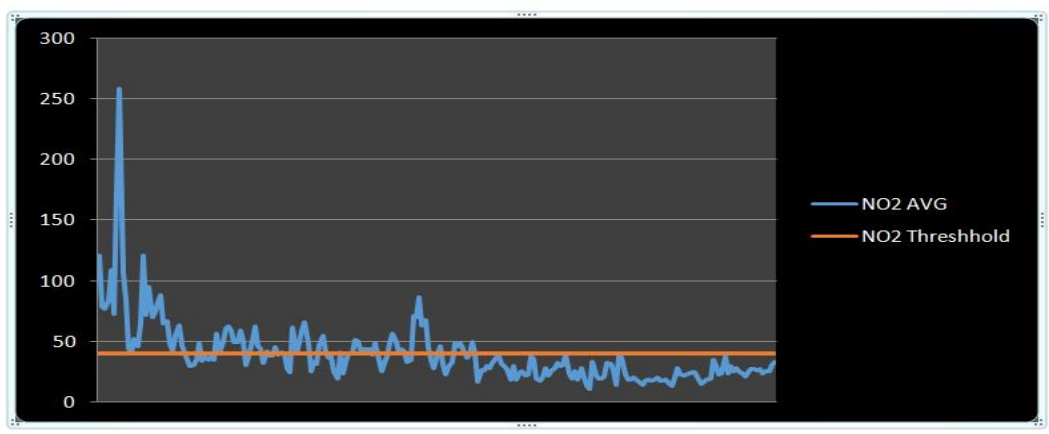

FIGURE 8. Level of $\mathrm{NO}_{2}$ during winter season 
$\mathrm{NO}_{2}$ has attained its peak during the winter season and then subsequently started declining but observed a rise in the summer season then started declining even below the standard threshold levels. It is observed that $\mathrm{NO}_{2}$ as a pollution parameter rises maximum in winter indicating high levels of pollution in winter season.

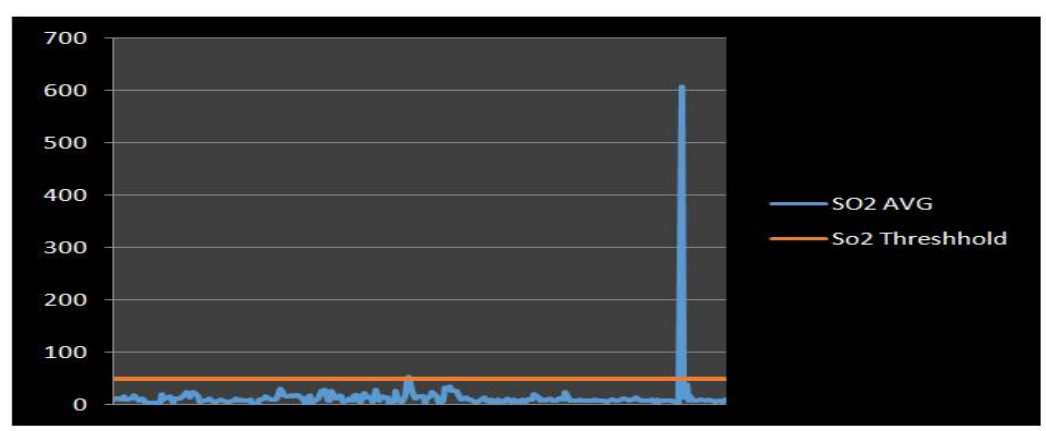

FIGURE 9. Level of $\mathrm{SO}_{2}$ in the East Delhi during autumn season

$\mathrm{SO}_{2}$ in East Delhi has remained low even below the threshold levels throughout the year but observes a sudden acute jump in autumn season owing to some ire or coal burning event.

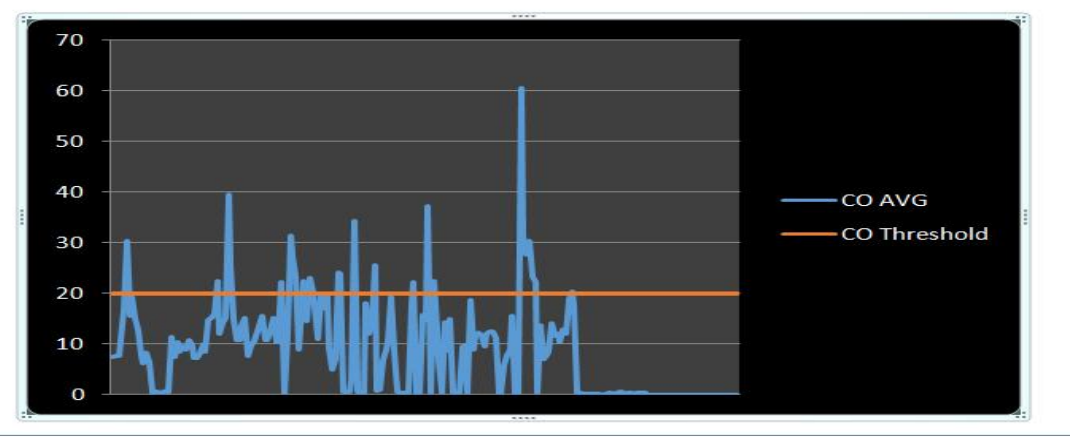

FIGURE 10. Level of CO in the East Delhi during summer season

CO most of the time has remained below the threshold levels in East Delhi. It increases in winter showing a signiicant rise during summer season but reaching very low levels compared to threshold level during autumn. It clearly depicts that in the rain the values of this parameter go down.

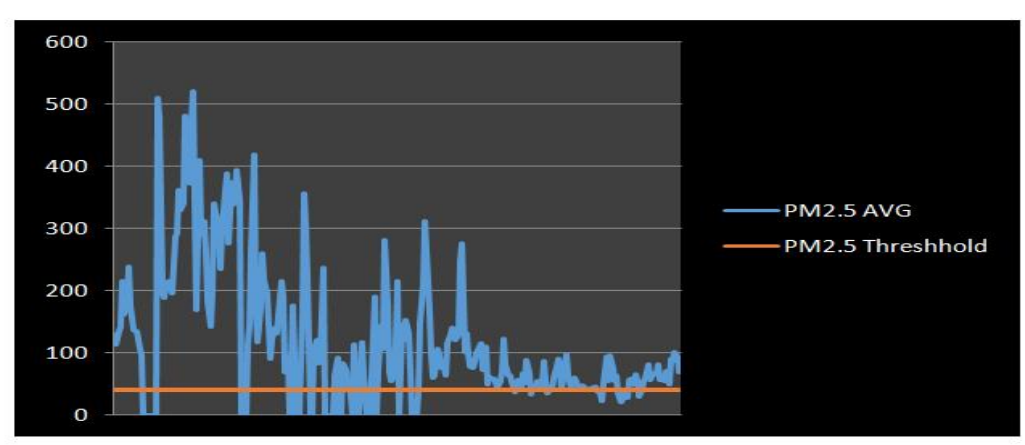

FIGURE 11 . PM 2.5 parameter in the East Delhi during all seasons 
PM 2.5 considered as a crucial parameter has remained very high throughout all seasons in East Delhi region showing a very high level of air pollution throughout the period in consideration. As it is observed that PM 2.5 also attains lower values compared to threshold level in some of the months, mostly during spring and summer season.

FORMULATION OF STUDY MODEL

Data related to health status and other socio-economic factors of household are collected using the household survey at the selected sites. The survey collected the sample of 214 households in the East Delhi region from the respective monitoring stations. The survey provides the data for winter season.

The data hence collected during the survey can be consolidated under the following variables:

\section{Endogenous Variables}

1. Health Status depicted by total number of sick days.

2. Mitigating Activity emulated by medical expenses which include:

- Travel cost to doctor's clinic

- Waiting time

- Doctor's fees charged

- Cost of medicines

3. Averting activities: These are relected by the following heads:

- Daily extra km travelled

- No. of days stayed indoor

- Use of mask, air purifier

- Mode of transport

\section{Exogenous Variables}

1. Outdoor Pollution: This parameter can be captured by air quality data provided by CPCB. This is data on SO2, NO2, PM 2.5, PM 10, CO, Ozone. In this study, we take PM 2.5 as an indicator of outdoor pollution.

2. Health stock Index: It is the index of chronic diseases; it also determines the health capital. The list of chronic diseases is as follows (in order): Asthma, BP, Heart Disease, Cancer, Eye disease, TB, Diabetes, and others. (This ranking has been conirmed by Dr. Peeyush Jain MD, DM. Director, Cardiology, Fortis Escorts Heart Institute, New Delhi).

3. Nutrition habits: An index is calculated using the nutrition habits of households like consumption of green leafy vegetables, olive and reined oil, fruits, nuts and processed food (in order). It also amalgamates consumption of vitamin supplements by individual. Higher the Index, poorer is the nutritional status of the person.

4. Indoor pollution: An Indoor Pollution index is calculated using the electronic appliances used by households, type of fuels used, garbage system used in the house and other sanitation habits.

5. Annual Income: Annual Income is reported from each household.

6. Awareness Index: It is the index of how aware the households are about the diseases caused due to air pollution.

The aim of the study can be accomplished by running the following regressions: 1 . Taking sick days as dependent variable:

$$
\begin{aligned}
& L n(\text { no.of sickdays })=\alpha 1+\beta 1 \ln (\text { outdoorpol } .)+\beta 2 \ln (\text { chronicdiseaseindex })+ \\
& \beta 3 \ln (\text { nutritionindex })+\beta 4 \ln (\text { indoorpol } .)+\beta 5 \ln (\text { awarenessofairbornediseases })+ \\
& \beta 6 \ln (\text { mitigationactivity })+\beta \ln (\text { income })+\beta 8 \ln (\text { avertingactivity })+\text { ui }
\end{aligned}
$$


2. Taking mitigating expenditure as dependent variable:

$\operatorname{Ln}($ mitigationactivity $)=\alpha 2+\beta 9 \ln ($ outdoorpol. $)+\beta 10 \ln ($ chronicdiseaseindex $)+$ $\beta 11 \ln ($ nutritionindex $)+\beta 12 \ln ($ indoorpol. $)+\beta 13 \ln ($ awarenessofairbornediseases $)+$ $\beta 14 \ln ($ no.of sickdays $)+\beta 15 \ln ($ income $)+\beta 16 \ln ($ avertingactivity $)+v i$

3. Taking averting activity as dependent variable:

$\ln ($ avertingactivity $)=\alpha 3+\beta 17 \ln ($ outdoorpol. $)+\beta 18 \ln ($ chronicdiseaseindex $)+$ $\beta 19 \ln ($ nutritionindex $)+\beta 20 \ln ($ indoorpol.$)+\beta 21 \ln$ (awarenessofairbornediseases $)+$ $\beta 22 \ln ($ mitigationactivity $)+\beta 23($ no.of sickdays $)+\beta 24 \ln ($ income $)+i$

\section{RESULTS}

\section{Correlation Analysis}

Indoor Pollution Index is positively related to Mitigating Activities Expenditure (0.186) and positively related to Sick Days (0.213). As indoor pollution surges, the expenditure on mitigating activities also increases. Increase in indoor pollution also leads to an increase in number of sick days. Health Stock Index is positively related to Mitigating Activities Expenditure (0.01342). It is also positively related to sick days $(0.07114)$. The more vulnerable a person is to chronic diseases (indicated by Health Stock Index), the higher would be his expenditure on mitigating activities. Similarly, a positive relation between Health Stock Index and Sick Days indicates an increase in sick leaves due to bad health stock. Air Borne Disease Awareness Index is negatively related to Mitigating Activities Expenditure $(-0.113)$. As awareness regarding air borne diseases develops, need for mitigating expenditure reduces.

TABLE 1. Results of descriptive statistics

\begin{tabular}{llll}
\hline \hline & Mean & Std. Deviation & $N$ \\
\hline Health status & 1.588239016292111 & .837153480870822 & 87 \\
Health Stock Index & 1.020567274111841 & .810780010197585 & 87 \\
Nutrition Index & 2.512916150899244 & .261346285357363 & 87 \\
Indoor Pollution Index & 2.486155381750613 & .139191497420920 & 87 \\
Income & 11.310772612412483 & 1.257762488855142 & 87 \\
Mitigating Expenditure & 5.566998207485893 & 2.104003344573943 & 87 \\
Awareness Index & -1.481987202861994 & .729178233310949 & 87 \\
PM 2.5 & 116.6982 & 108.50448 & 87 \\
\hline \hline
\end{tabular}

Source: DJP RI, March 2016

TABLE 2 . Indoor air pollution and mitigating (0.186)

\begin{tabular}{lll}
\hline \hline & Pollution Index & Mitigating Expenditure \\
\hline Pollution Index & 1 & \\
Mitigating Expenditure & 0.186090375 & 1 \\
\hline \hline
\end{tabular}

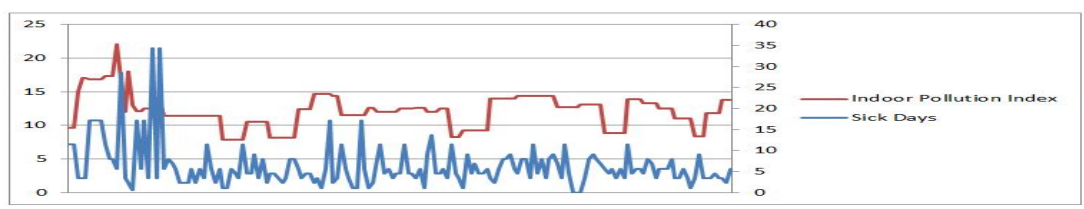

FIGURE 12. Indoor air pollution and mitigating (0.186) 
TABLE 3. Indoor air pollution and sick days (0.213)

\begin{tabular}{lll}
\hline \hline & Pollution Index & Sick Days \\
\hline Pollution Index & 1 & \\
Sick Days & 0.213134 & 1 \\
\hline \hline
\end{tabular}

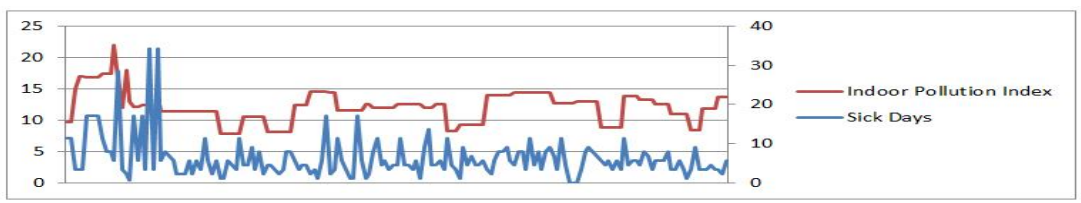

FIGURE 13. Indoor air pollution and sick days (0.213)

TABLE 4. Mitigating expenditure and health stock index (0.01342)

\begin{tabular}{lll}
\hline \hline & Mitigating Expenditure & Health Stock Index \\
Mitigating Expenditure & 1 & \\
Health Stock Index & 0.0134253 & 1 \\
\hline \hline
\end{tabular}

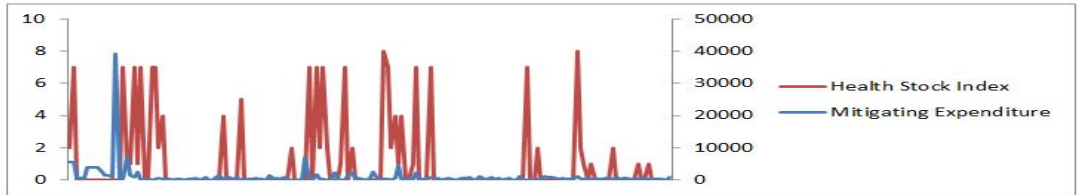

FIGURE 14 . Mitigating expenditure and health stock index (0.01342)

TABLE 5. Mitigating expenditure and sick days (0.07114)

\begin{tabular}{lll}
\hline \hline & Mitigating Expenditure & Sick Days \\
Mitigating Expenditure & 1 & \\
Sick Days & 0.07114398 & 1 \\
\hline \hline
\end{tabular}

\section{Sick Days as Dependent Variable}

Above table shows that Nutrition Index holds a positive relationship with number of sick days indicating that as value of nutrition index increases by 1 percent, showing a poor nutrition status, the number of sick days also rises by 0.374 percent. Number of sick days is also positively related to Indoor Pollution Index showing that as indoor pollution increases by 1 percent, the number of sick days rises by 0.389 percent. Number of sick days is also positively related to health stock indicating that 1 percent rise in health stock (a person suffering from chronic diseases) would lead to 0.207 percent increase in sick days. Income holds a negative relationship with number of sick days. High income would imply lesser number of sick days. PM 2.5, an indicator of ambient pollution holds a positive relationship with sick days. One percent rise would lead to 0.001 percent rise in number of sick days. Mitigating Expenditure shows a positive relationship with number of sick days. A one percent rise in mitigating expenditure would lead to a 0.260 percent rise in sick days. 
TABLE 6. Air borne awareness diseases and mitigating expenditure (-0.113)

\begin{tabular}{lll}
\hline \hline & Mitigating Expenditure & Awareness Index \\
Mitigating Expenditure & 1 & \\
Awareness Index & -0.113245 & 1 \\
\hline \hline
\end{tabular}

TABLE 7 . Results for main impact of pollution and nutrition on sick days

\begin{tabular}{|c|c|c|c|c|c|c|c|}
\hline \multirow{2}{*}{$\frac{\text { Model }}{\text { Model }}$} & \multicolumn{2}{|c|}{ Unstandardized Coefficients } & \multirow{2}{*}{$\begin{array}{l}\text { Standardized Coefficients } \\
\text { Beta }\end{array}$} & \multirow[t]{2}{*}{$\mathrm{T}$} & \multirow{2}{*}{$\begin{array}{l}\text { Sig. } \\
\text { Lower Bound }\end{array}$} & \multicolumn{2}{|c|}{ 95.0\% Confidence Interval for B } \\
\hline & Beta & Std. Error & & & & Upper & \\
\hline (Constant) & 2.559 & 2.686 & & .953 & .350 & -2.972 & 8.090 \\
\hline Health Stock Index & .207 & .140 & .200 & 1.478 & .152 & -.081 & .495 \\
\hline Nutrition Index & .374 & .498 & .117 & .751 & .460 & -.652 & 1.400 \\
\hline Indoor Pollution Index & .389 & .877 & .065 & .443 & .662 & -2.194 & 1.417 \\
\hline Income & -.228 & .103 & -.342 & -2.222 & .036 & -.439 & -.017 \\
\hline PM 2.5 & .001 & .001 & .085 & .580 & .567 & -.002 & .003 \\
\hline
\end{tabular}

Dependent variable: Health status

\section{Mitigating Expenditure as Dependent Variable}

Above table shows that Nutrition Index holds a positive relationship with mitigating expenditure indicating that as value of nutrition index increases by 1 percent, showing a poor nutrition status, the expenditure also rises by 2.108 percent. Mitigating Expenditure is positively related to Indoor Pollution Index showing that as indoor pollution increases by 1 percent the expenditure rises by 1.167 percent.

Mitigating Expenditure is also positively related to health stock indicating that 1 percent rise in health stock (a person suffering from chronic diseases) would lead to 0.379 percent increase in expenditure. Income holds a positive relationship with expenditure to mitigate. High income would imply more expenditure. PM 2.5, an indicator of ambient pollution holds a negative relationship with sick days. One percent rise would lead to 0.04 percent fall in expenditure. Mitigating Expenditure shows a positive relationship with averting activity. A one percent rise in averting action would lead to a 0.305 percent rise in expenditure.

\section{Averting Activity as a Dependent Variable}

Nutrition Index holds a positive relationship with averting activities indicating that as value of nutrition index increases by 1 percent, the individual will avert more by 0.59 per Averting activity is also positively related to Indoor Pollution Index showing that as indoor pollution increases by 1 percent the action to avert rises by 0.228 percent. There exists a negative relation between averting activity and health stock index. More the aversion, lesser would be the chances of chronic diseases. Income holds a positive relationship with averting activity. High income would imply more chances to avert. PM 2.5, an indicator of ambient pollution holds a negative relationship with averting activities. One percent rise would lead to 0.001 percent fall in number of aversion actions. Mitigating Expenditure shows a positive relationship with averting activity. A one percent rise in mitigating expenditure would lead to a 0.033 percent rise in aversion. It is important to note that the data collected for averting activities like Daily extra km travelled, no. of days stayed indoors, use of mask or air purifier, mode of transport faced very low responses across household. The low t-values could be attributed to this particular limitation which was faced in the survey. 
TABLE 8. Model summary

\begin{tabular}{|c|c|c|c|c|c|c|c|c|c|c|}
\hline \multicolumn{5}{|c|}{ Model } & \multicolumn{5}{|c|}{ Model Change } & \multirow[t]{2}{*}{ Statistics Durbin-Watson } \\
\hline & $R R^{2}$ & Adjusted $R^{2}$ & Std. Error & $R^{2}$ & F-Change & df1 & df2 & Sig. & F-Change & \\
\hline 1 & $.753 a$ & .567 & .446 & .623 & .567 & 4.679 & 7 & 25 & .002 & 2.589 \\
\hline
\end{tabular}

Predictors: (Constant), PM 2.5, Awareness Index, Health Stock Index, Nutrition Index, Indoor Pollution Index, Mitigating Expenditure, Income Dependent Variable: Health status

TABLE 9. One-way ANOVA analysis

\begin{tabular}{llllll}
\hline \hline Model & Sum of Squares & Df & Mean Square & $F$ & Sig. \\
\hline 1 Regression & 12.719 & 7 & 1.817 & 4.679 & .002 \\
Residual & 9.708 & 25 & .388 & & \\
Total & 22.426 & 32 & & & \\
\hline \hline
\end{tabular}

Averting activity is also positively related to Indoor Pollution Index showing that as indoor pollution increases by 1 percent the action to avert rises by 0.228 percent. There exists a negative relation between averting activity and health stock index. More the aversion, lesser would be the chances of chronic diseases. Income holds a positive relationship with averting activity. High income would imply more chances to avert. PM 2.5, an indicator of ambient pollution holds a negative relationship with averting activities. One percent rise would lead to 0.001 percent fall in number of aversion actions. Mitigating Expenditure shows a positive relationship with averting activity. A one percent rise in mitigating expenditure would lead to a 0.033 percent rise in aversion. It is important to note that the data collected for averting activities like Daily extra km travelled, no. of days stayed indoors, use of mask or air puriier, mode of transport faced very low responses across household. The low $t$-values could be attributed to this particular limitation which was faced in the survey.

\section{Discussion}

Nutrition Status

In the present study, data were compiled on habits that affect health in general, including frequency of consumption of fruits, nuts, vegetables especially green leafy vegetables as also processed foods. It was found that majority of the households consumed green leafy vegetables (68\%), other vegetables $(78.0 \%)$, fruits $(66.0 \%)$ and nuts $(33.33 \%)$ on a daily basis.

These foods are a rich source of protective micronutrients and antioxidants providing immunity against damaging effects of air pollution. A high fruit and vegetable diet would lead to an enrichment in micronutrient status (Vitamin C, E, B group Vitamins, and Carotenoids), corresponding to the lesser risk of asthma exacerbation (Péter et al., 2015). Majority of the households (51.02\%) reported consuming processed foods rarely/never, whereas $77.08 \%$ of the households were consuming some vegetable oils rich in PUFAs or olive oil. Several intervention studies in humans have found that nutrients like antioxidants and omega- 3 fatty acids may lessen the damage induced by air pollution. Antioxidant supplementation may be helpful in reducing air pollution-induced oxidative stress in the body, by both direct and indirect mechanisms.(8) In the present study, Vitamin A supplements were consumed by $12.5 \%$, Vitamin C supplements by $19.6 \%$ and Vitamin E supplements by $10.7 \%$ of the subjects. Increased intake of antioxidants, as well as other anti-inflammatory nutrients, may attenuate air-pollution induced oxidative stress and in- 
TABLE 10 . Results for main impact of pollution and nutrition on mitigating expenditure

\begin{tabular}{|c|c|c|c|c|c|c|c|}
\hline \multirow{2}{*}{$\begin{array}{l}\text { Model } \\
1 \text { (Constant) }\end{array}$} & \multicolumn{2}{|c|}{ Unstandardized Coefficients } & \multirow[t]{2}{*}{ Standardized Coefficients } & \multirow{2}{*}{$\begin{array}{l}\mathrm{T} \\
.988\end{array}$} & \multirow{2}{*}{$\begin{array}{l}\text { Sig. } \\
.333\end{array}$} & \multicolumn{2}{|c|}{ 95.0\% Confidence Interval for B } \\
\hline & 6.925 & 7.012 & & & & -7.547 & 21.397 \\
\hline Health Stock Index & .379 & .367 & .146 & 1.032 & .312 & -1.137 & .379 \\
\hline Nutrition Index & 2.108 & 1.277 & .262 & 1.651 & .112 & -4.743 & .527 \\
\hline Indoor Pollution Index & 1.167 & 2.254 & .077 & .518 & .609 & -5.820 & 3.486 \\
\hline Income & .476 & .275 & .285 & 1.733 & .096 & -.091 & 1.044 \\
\hline Awareness Index & .343 & .428 & .119 & .802 & .430 & -.541 & 1.228 \\
\hline Averting Index & .305 & .619 & .078 & .493 & 627 & -.973 & 1.583 \\
\hline
\end{tabular}

Dependent variable: Mitigating Expenditure

TABLE 11. Model summary

\begin{tabular}{lllllllllll}
\hline \hline \multicolumn{4}{c}{ Model } & \multicolumn{4}{c}{ Model Change } & \multicolumn{1}{c}{ Statistics Durbin-Watson } \\
\hline & $R^{2}$ & Adjusted $R^{2}$ & Std. Error & $R^{2}$ & F-Change & df1 & df2 & Sig. & F-Change \\
\hline 1 & .752 & .565 & .421 & 1.601 & .565 & 3.903 & 8 & 24 & .004 & 2.257 \\
\hline \hline
\end{tabular}

Predictors: (Constant), Averting Index, Health Stock Index, Indoor Pollution Index, Health status, pm2.5, Awareness Index, Nutrition Index, Income Dependent variable: Mitigating Expenditure

\section{FINDINGS}

The results indicate that health is positively related or gets affected by indoor pollution. The study also indicated that negative effect on health augments the expenditure on mitigating activities.

Increased incidence of chronic diseases (Asthma, TB, Heart Diseases, Cancer etc.) indicated by health stock index would imply higher expenditure on mitigating activities and increase in number of sick days.

The results conform to the fact that a fall in natural and biological resistance to illness as indicated by nutrition index accounts for a higher expenditure on mitigating activities in form of medical expenses.

No other study in any part of India has incorporated the nutrition variable as a measure of health conditions in the model. It becomes a different approach to see how nutrition along with pollution factor helps decide the health status of an individual.

\section{CONCLUSION}

This study provides a rough measure of health beneits from alleviation in air pollution from the current level to the national ambient air quality standard level in East Delhi. The study also finds that nutrition habits of individuals play a decisive role in decreasing the number of sick days along with the indoor and outdoor pollution. This study would recommend that government should take steps to curtail outdoor ambient pollution by introducing various renewable sources of energy which would bring the levels of PM2.5, PM10 and $\mathrm{NO}_{2}$ to an acceptable range. The analysis also advocates that healthy food habits should be embraced by people so that they are less affected by the impact of air pollution and further bring down their expenses on medical treatment by minimizing the number of sick days.

\section{LIMITATIONS AND RECOMMENDATIONS}

This study has provided some promising results, yet there are still some limitations. Due to scarcity of time and resources an investigation of all the factors concerned 
TABLE 12. One-way ANOVA analysis

\begin{tabular}{llllll}
\hline \hline Model & Sum of Squares & Df & Mean Square & $F$ & Sig. \\
\hline Regression & 80.097 & 8 & 10.012 & 3.903 & .004 \\
Residual & 61.561 & 24 & 2.565 & & \\
Total & 141.659 & 32 & & & \\
\hline \hline
\end{tabular}

TABLE 13. Results for main impact of pollution and nutrition on averting activity

\begin{tabular}{|c|c|c|c|c|c|c|c|}
\hline Model & \multicolumn{2}{|c|}{ Unstandardized Coefficients } & \multirow[t]{2}{*}{ Standardized Coefficients } & \multirow{2}{*}{$\begin{array}{l}\mathrm{T} \\
-.932\end{array}$} & \multirow{2}{*}{$\begin{array}{l}\text { Sig. } \\
361\end{array}$} & \multicolumn{2}{|c|}{ 95.0\% Confidence Interval for B } \\
\hline 1 (Constant) & -2.149 & 2.305 & & & & -6.907 & 2.609 \\
\hline Health Stock Index & -.019 & .123 & -.029 & -.156 & .877 & -.273 & .235 \\
\hline Nutrition Index & .599 & .425 & .291 & 1.411 & .171 & -.277 & 1.476 \\
\hline Indoor Pollution Index & .228 & .742 & .059 & .308 & .761 & -1.304 & 1.761 \\
\hline Income & .070 & .095 & .163 & .738 & .468 & -.125 & .265 \\
\hline Awareness Index & .169 & .138 & .230 & 1.226 & .232 & -.116 & .455 \\
\hline Health Status & .053 & .169 & .082 & .312 & .757 & -.295 & .401 \\
\hline Mitigating Expenditure & .033 & .067 & .128 & .493 & .627 & -.105 & .170 \\
\hline
\end{tabular}

Dependent variable: Averting Index

TABLE 14. Model summary

\begin{tabular}{lllllllllll}
\hline \hline \multicolumn{4}{c}{ Model } & \multicolumn{3}{c}{ Model Change } & \multicolumn{3}{c}{ Statistics Durbin-Watson } \\
\hline & $R R^{2}$ & Adjusted $R^{2}$ & Std. Error & $R^{2}$ & F-Change & df1 & df2 & Sig. & F-Change \\
\hline 1 & .534 & .285 & .047 & .52545 & .285 & 1.195 & 8 & 24 & .343 & 1.452 \\
\hline \hline
\end{tabular}

Predictors: (Constant), Mitigating Expenditure, Income, Health Stock Index, Indoor Pollution Index, Awareness Index, pm2.5, Nutrition Index, Health status Dependent Variable: Averting Index

TABLE 15. Units of variables

\begin{tabular}{lll}
\hline \hline S.No. & Variables & Unit \\
\hline 1. & Mitigating expenditures & Rs \\
2. & No. of sick days & Days \\
3. & Nutrition Index & $\mathrm{NA}$ \\
4. & Indoor Pollution Index & $\mathrm{NA}$ \\
5. & Health Stock Index & $\mathrm{NA}$ \\
7. & Age & Years \\
8. & $\mathrm{SO}_{2}$ & $\mu \mathrm{g} / \mathrm{m}^{3}$ \\
9. & $\mathrm{NO}_{2}$ & $\mu \mathrm{g} / \mathrm{m}^{3}$ \\
10. & $\mathrm{PM} 10^{3}$ & $\mu \mathrm{g} / \mathrm{m}^{3}$ \\
11. & $\mathrm{PM} 2.5$ & $\mu \mathrm{g} / \mathrm{m}^{3}$ \\
\hline \hline
\end{tabular}

with air pollution were not studied, hence, further investigation is required for conclusive evidence in this regard.

\section{REFERENCES}

Adhikari, Naveen. 2012. Measuring the health benefits from reducing air pollution in Kathmandu Valley. South Asian Network for Development and Environmental Economics (SANDEE), Kathmandu, NP.

Cropper, Maureen L. 1981. Measuring the benefits from reduced morbidity. The American Economic Review 71, no. 2: 235-240. 
Dasgupta, Purnamita. 2004. Valuing health damages from water pollution in urban Delhi, India: A health production function approach. Environment and Development Economics 9, no. 1: pp. 83-106. DOI: 10.1017/S1355770X03001098

Freeman III, A. Myrick, Robert H. Haveman, and Allen V. Kneese. 1973. Economics of environmental policy. New York, NY: John Wiley and Sons, Inc.

Gerking, Shelby, and Linda R. Stanley. 1986. An economic analysis of air pollution and health: The case of St. Louis. The Review of Economics and Statistics 86, no. 1: pp. 115-121. D0I: 10.2307/1924934

Grossman, Michael. 1972. On the concept of health capital and the demand for health. Journal of Political Economy 80, no. 2: pp. 223-255. DOI: $10.1086 / 259880$

Gupta, Usha. 2008. Valuation of urban air pollution: A case study of Kanpur City in India. Environmental and Resource Economics 41, no. 3: 315-326. DOI: 10.3390/nu7125539

Haque, AK Enamul, Maddipati Narasimha M, and Priya Shyamsundar. 2011. Environmental valuation in South Asia. New Delhi, IN: Cambridge University Press.

Harrington, Winston, and Paul R. Portney. 1987. Valuing the benefits of health and safety regulation. Journal of Urban Economics 22, no. 1: 101-112.

Kumar, Surender, and Rao DN. 2001. Valuing the beneficts of air pollution abatement using a health production function a case study of Panipat thermal power station, India. Environmental and Resource Economics 20, no. 2: 91-102. DOI: 10.1023/A:1012635627808

Min Bikram Malla Thakuri. 2009. Revisiting the need of improved stoves: Estimating health, time and carbon bene-

fits. SANDEE working aper no. 44-09, South Asian Network for Development and Environmental Economics (SANDEE), Kathmandu, Nepal.

Murty, Maddipati N. 2009. Environment, sustainable development and well-being: Valuation, taxes and incentives. New Delhi, IN: Oxford University Press.

Péter, Szabolcs, Fernando Holguin, Lisa G. Wood, Jane E. Clougherty, Daniel Raederstorff, Magda Antal, Peter Weber, and Manfred Eggersdorfer. 2015. Nutritional solutions to reduce risks of negative health impacts of air pollution. Nutrients 7, no. 12: 10398-10416. DOI: 10.3390/nu7125539

— This article does not have any appendix. - 